\title{
ASPECTOS METODOLÓGICOS DA EXTRAÇÃO DE LIPÍDEOS DO TECIDO MUSCULAR DE JUVENIS DE PEIXES PARA ANÁLISES ISOTÓPICAS DE AMOSTRAS DESENGORDURADAS
}

\author{
DE CASTRO, Mateus Brandão Flávio ${ }^{1}$ \\ DUCATTI, Carlos ${ }^{2}$ \\ TAKATA, Rodrigo ${ }^{3}$ \\ JOMORI, Rosangela Kiyoko ${ }^{4}$
}

\begin{abstract}
RESUMO: Os lipídeos desempenham diversas funções fisiológicas e estruturais de grande importância para os animais, sendo encontrados em seus tecidos sob a forma de óleos e gorduras. A extração de lipídeos pode ser feita por diferentes métodos, sendo esses selecionados de acordo com os objetivos da análise. O objetivo do trabalho foi avaliar diferentes protocolos de extração do lipídeo, por método a frio, associando frequência de exposição e quantidades do solvente visando à aplicação deste procedimento para análises isotópicas de carbono e nitrogênio de amostras desengorduradas. Amostras de tecido muscular de juvenis de pacu P. mesopotamicus foram submetidas à frequência de extração, com solvente hexano, de 3, 6, e 9 vezes e quantidades de solventes 5,10 e $20 \mathrm{ml} / \mathrm{g}$ de amostra seca, em esquema fatorial 3x3, com 3 repetições. Para os valores de Carbono-13 e Nitrogênio-15 das amostras desengorduradas, não foram observadas diferenças entre as frequências de extração $(p>0,05)$ e as quantidades de solvente $(\mathrm{p}>0,05)$. Por outro lado, amostras desengorduradas mostraram-se mais ricas em Carbono-13 que a amostra engordurada (controle) $(\mathrm{p}<0,05)$; e sem diferenças para os isótopos de Nitrogênio-15 ( $p>0,05)$. Os protocolos de extração de lipídeos foram eficientes para o tecido alvo estudado em análises isotópicas, alterando os valores de $\delta^{13} \mathrm{C}$ da amostra desengordurada sem modificar os valores de $\delta^{15} \mathrm{~N}$.
\end{abstract}

Palavras-chave: Hexano. Métodos de extração. Lipídeos. Isótopos estáveis.

SUMMARY: Lipid plays several physiological and structural roles in animal body and can be found in tissue in the form of oils and fats. It's extraction may be carried out through by different methods and each one is appropriate depending on objective of analyze. Therefore, the objective of this study was to evaluate the frequency of extraction of lipid in different amounts of solvent. The samples of muscle tissue were submitted to the following protocols: Frequency extraction with hexane of 3, 6, and 9 times and quantities of solvents of 5, 10 and $20 \mathrm{~mL}$ for each $1 \mathrm{~g}$ of sample, in a $3 \times 3$ factorial arrangement with 3 repetitions. There were no difference for the extraction frequency $(p>0.05)$ and quantities of hexane ( $>>0.05)$ for the Carbon-13 and Nitrogen-15 values. In comparison to the sample with lipid, the tissue lipid-free was richer in Carbon-13 ( $<<0.05)$ and there was no difference between the Nitrogen15 values $(p>0.05)$. The extraction of lipid was important to the isotopic analysis and the protocols evaluated in this study can be used successfully to this tissue.

Keyword: Hexane. Extraction methods. Lipids. Stable isotopic.

\footnotetext{
${ }^{1}$ Graduação em Medicina Veterinária- Faculdade Dr. Francisco Maeda, FAFRAM/ FE, Ituverava, SP (Trabalho de Conclusão de Curso).

${ }^{2}$ Professor Doutor do Departamento de Física e Biofísica, Supervisor do Centro de Isótopos Estáveis, IB/UNESP, Botucatu, SP.

${ }^{3}$ Pós-Doutorando do Laboratório de Aquacultura da Universidade Federal de Minas Gerais, Belo Horizonte, Minas Gerais.

${ }^{4}$ Professora Doutora da Faculdade Dr Francisco Maeda, Laboratório de Aquicultura, FAFRAM/ FE Ituverava, SP. Pós-Doutoranda do Centro de Isótopos Estáveis - Instituto de Biociências/ UNESP, Botucatu, SP. Autor Correspondente: jomori@netsite.com.br.
} 


\section{INTRODUÇÃO}

Lipídeos são formados por carbono, hidrogênio e oxigênio e são encontrados em diversos alimentos na forma de gordura e/ou óleos. Esse nutriente é considerado essencial para os animais e desempenham tanto papel energético quanto estrutural (TOCHER, 2003, 2010). As gorduras e óleos são formados por três moléculas de ácidos graxos ligados a uma molécula de glicerol podendo ter de quatro a vinte e quatro ou mais átomos de carbonos sendo saturados ou insaturados (NELSON; COX, 2006).

O valor nutritivo dos alimentos está diretamente relacionado com sua digestibilidade, composição química e energética, sendo os ensaios de nutrição e a análise bromatológica as ferramentas responsáveis por essa investigação. Os lipídeos apresentam uma classe vasta que compreende as gorduras, cujas funções são de grande importância para o organismo, sendo, por isso, de grande interesse o conhecimento acerca do teor de gordura presente no alimento. (ABIMORAD; CARNEIRO, 2007; MANZKE et al. 2008).

Os isótopos estáveis de carbono-13 $\left(\delta^{13} \mathrm{C}\right)$ e de nitrogênio-15 $\left(\delta^{15} \mathrm{~N}\right)$ constituem numa ferramenta analítica que permite rastrear as fontes energéticas na cadeia alimentar de um ecossistema (GU et al., 1994). Adicionalmente, pode se citar o uso desta técnica em estudos de nutrição, mais especificamente na assimilação e metabolismo dos nutrientes (CONCEIÇÃO et al., 2007; JOMORI et al., 2008). Alguns cuidados e critérios nas etapas de preparação das amostras biológicas devem ser considerados para evitar a influência de fatores externos nos resultados da composição isotópica de uma amostra biológica (DUCATTI, 2007; SOTIROPOULOS et al., 2004). Um destes fatores refere-se remoção da fração lipídica das amostras (FOCKEN, 2004; GAVE-SIESSEGGER et al., 2004 a, b). A extração dos lipídeos pode ter algumas consequências no valor isotópico do carbono-13 das amostras biológicas, baseando-se no fato de que esse nutriente é mais pobre em carbono-13 que os carboidratos e as proteínas. Em adição, amostras submetidas à extração lipídica podem se tornar mais enriquecidas em nitrogênio-15 pela lixiviação de determinados aminoácidos durante o procedimento da extração, alterando também a composição isotópica do animal em relação a esse isótopo (SOTIROPOULOS et al., 2004).

A extração da gordura da amostra é um procedimento comum em análise de alimentos e de materiais coletados em experimentos de alimentação e de nutrição animal (A.O.A.C., 2003). Existem diferentes metodologias de extração, por método a quente (método clássico de Soxhlet) e a frio (FOLCH et al., 1957; BLIGH; DYER, 1959), com o uso de diferentes solventes (NELSON, 1991). Radim (1981) sugeriram um método mais simples e menos tóxico, baseado no uso de uma mistura de n-hexanoisopropanol. O hexano é um solvente universal e menos tóxico do que os demais, sendo usado com frequência na extração de oleaginosas (GANDHI et al., 2003).

Assim, é importante avaliar as metodologias de extração de lipídeos buscando procedimentos práticos e apropriados para aplicação em análises isotópicas, buscando evitar possíveis erros analíticos resultantes dos métodos de extração da gordura das amostras. O presente trabalho visa obter informações quanto à extração da fração lipídica, por método a frio, com os objetivos de: 1) verificar a eficiência de remoção de gordura das amostras por diferentes protocolos de extração e; 2) avaliar o efeito da extração de gordura sobre a composição isotópica do tecido muscular de juvenis de pacu P.mesopotamicus, visando à aplicação deste procedimento na técnica dos isótopos estáveis em estudos de alimentação e nutrição de peixes.

\section{MATERIAL E MÉTODOS}

O estudo foi realizado no Laboratório de Aqüicultura da Faculdade "Dr. Francisco Maeda" da 
Fundação Educacional de Ituverava-SP (FAFRAM/ FE).

\section{Amostra e extração lipídica}

O material biológico constitui-se de amostras de tecido muscular de juvenis de pacu Piaractus mesopotamicus. Os peixes analisados apresentavam peso de $206 \pm 32 \mathrm{~g}$ e foram alimentados com dieta contendo $27 \%$ de proteína bruta, 2,6 \% de extrato etéreo, 3,1\% de fibra bruta, $6,9 \%$ de matéria mineral e $4.350,3 \mathrm{cal} / \mathrm{g}$ de energia bruta. A dieta era composta principalmente por ingredientes a base de plantas do ciclo fotossintético $\mathrm{C}_{3}$, contendo farelo de soja, farelo de trigo, quirera de arroz, farinha de peixe, óleo de soja, premix vitamínico e mineral e suplementação com aminoácidos (metionina e lisina). No momento da coleta, os animais já recebiam a respectiva dieta por 90 dias.

As amostras do tecido muscular dos juvenis de pacu foram retiradas da porção dorsal. O material coletado foi seco em estufa de circulação de ar a $50 \pm 5^{\circ} \mathrm{C}$. Posteriormente, as amostras foram moídas (em moinho criogênico), sendo uma parte reservada para a análise isotópica do material engordurado e a outra para os diferentes protocolos de extração da gordura com hexano, pelo método a frio.

As amostras foram submetidas às extrações pelo hexano na frequência de exposição de 3, 6 e 9 vezes utilizando as quantidades de solvente de 5,10 e $20 \mathrm{~mL}$ por grama de amostra seca. O procedimento de extração foi realizado em temperatura ambiente e para cada tempo de exposição ao solvente, as amostras foram mantidas por cinco minutos sob agitador magnético ( 400 a 450 RPM), retirando-se o sobrenadante após um período de descanso ( 10 minutos, para a decantação do material particulado em suspensão). Os protocolos de extração de gordura foram delineados em esquema fatorial 3 x 3 (frequência de extração x quantidade de solvente), com três repetições em cada tratamento.

Após o procedimento da extração, as amostras desengorduradas foram novamente moídas, em almofariz, e separadas em dois lotes. Um foi destinado para a determinação do possível teor de gordura remanescente na amostra e a outra foi encaminhada para as análises isotópicas. A determinação do teor dos lipídios das amostras desengorduradas pelos protocolos testados foi realizada para quantificar o conteúdo de gordura remanescente nas respectivas amostras, verificando assim a eficiência de extração do método a frio utilizado neste protocolo.

O teor de lipídeo das amostras desengorduradas e do controle (amostra engordurada), expresso em porcentagem com base na matéria seca, foi determinado pelo método de Soxhlet (AOAC, 2003), no Laboratório de Nutrição Animal da Faculdade de Ciências Agrárias e Veterinárias da UNESP, em Jaboticabal, SP.

\section{Análises Isotópicas}

Para análise da composição isotópica, as amostras secas e moídas foram pesadas ( $60 \mu \mathrm{g}$ para análise do isótopo de carbono e $500 \mu \mathrm{g}$ para a de nitrogênio) e acondicionadas em cápsulas de estanho. A determinação da composição isotópica das amostras baseia-se nas razões ${ }^{13} \mathrm{C} /{ }^{12} \mathrm{C}$ e ${ }^{15} \mathrm{~N} /{ }^{14} \mathrm{~N}$, que são mensuradas comparativamente com a razão ${ }^{13} \mathrm{C} /{ }^{12} \mathrm{C}$ do padrão internacional PDB (Fóssil Belemnitella americana da formação cretácea Pee Dee do Sul da Carolina/USA) e com a razão ${ }^{15} \mathrm{~N} /{ }^{14} \mathrm{~N}$ do padrão internacional Nitrogênio Atmosférico, respectivamente. A comparação relativa entre a amostra e o padrão expressa-se, na terminologia isotópica, como enriquecimento relativo ou delta per mil, mensurada pela expressão: $\delta^{13} \mathrm{C}$ ou $\delta^{15} \mathrm{~N}=$ [(R amostra/ $\mathrm{R}$ padrão)-1] x $10^{3}$, na qual, $\mathrm{R}$ é a razão isotópica $\left({ }^{13} \mathrm{C} /{ }^{12} \mathrm{C}\right.$ ou ${ }^{15} \mathrm{~N} /{ }^{14} \mathrm{~N}$ ) da amostra e do padrão, respectivamente, e $\delta{ }^{13} \mathrm{C}$ ou $\delta^{15} \mathrm{~N}$ é o enriquecimento isotópico (delta per mil) da amostra relativo ao padrão PDB ou nitrogênio atmosférico, respectivamente (DUCATTI et al., 1982). As determinações dos valores isotópicos das amostras foram efetuadas em Espectrômetro de Massa 
de Baixa Resolução, com erro analítico da ordem de 0,2\%o, no Centro de Isótopos Estáveis do Instituto de Biociências da UNESP, Botucatu, SP.

\section{Análise Estatística}

Os dados isotópicos e os de teor de gordura referentes às amostras desengorduradas, pelo método de extração a frio em teste, foram analisados em delineamento inteiramente casualizado em esquema fatorial $3 \times 3$, considerando três frequências de exposição ao solvente hexano (3, 6 e 9) e três quantidades de solvente $(5,10$ e $20 \mathrm{~mL} / \mathrm{g}$ de amostra seca). A comparação do teor de lipídeos entre a amostra engordurada (controle) e as desengorduradas foi realizada em delineamento inteiramente casualizado, constituído de três tratamentos (amostra engordurada e amostras desengorduradas pela frequência de extração e pela quantidade de solvente), com nove repetições cada. Os dados foram submetidos à análise de variância paramétrica, pelo programa estatístico SAS - Statistical Analysis System 8.0 (SAS Institute). As pressuposições de análises de Normalidade dos Erros (Cramer Von Misess) e de Homocedasticidade das variâncias (Levene) foram averiguadas antes da aplicação dos testes estatísticos.

\section{RESULTADOS E DISCUSSÃO}

As análises estatísticas dos valores de $\delta^{13} \mathrm{C}$ (carbono-13) do tecido muscular indicaram que não houve diferenças significativas para a quantidade de solvente $(p>0,05)$ e a frequência de extração ( $p>0,05)$, e nem o efeito da interação entre os fatores ( $p>0,05$; Tabela 1).

A composição isotópica, em carbono-13, do músculo desengordurado variou de -23,37 a -23,21\%o entre os protocolos de extração da fração lipídica (Tabela 1), com uma variação de apenas 0,16\%o.

Tabela 1. Análise estatística dos valores de $\delta^{13} \mathrm{C}$ do tecido muscular de juvenis de pacu P. mesopotamicus, considerando amostras desengorduradas por diferentes protocolos de extração da fração lipídica.

\begin{tabular}{|c|c|c|}
\hline \multirow[b]{2}{*}{ Fatores } & \multicolumn{2}{|c|}{ Estatística } \\
\hline & Valor de F & Valor de $\mathbf{p}$ \\
\hline Quantidade de solvente $(\mathrm{Q})$ & 0,45 & 0,6438 \\
\hline Frequência de Extração (F) & 0,28 & 0,7586 \\
\hline Interação Q x F & 0,73 & 0,5851 \\
\hline Coeficiente de Variação (\%) & 1,53 & \\
\hline Médias para & & \\
\hline \multicolumn{3}{|c|}{ Quantidade de Solvente (mL/g de amostra seca) } \\
\hline $5 \mathrm{~mL}$ & & \\
\hline $10 \mathrm{~mL}$ & & \\
\hline $20 \mathrm{~mL}$ & & \\
\hline
\end{tabular}

Frequência de Extração (nº de exposição ao solvente)

\begin{tabular}{ll}
3 vezes & $-23,37 \pm 0,15$ \\
6 vezes & $-23,21 \pm 0,22$ \\
9 vezes & $-23,33 \pm 0,07$ \\
\hline
\end{tabular}

- Extração de lipídeos por método a frio, com o solvente hexano. 
Para os valores de $\delta^{15} \mathrm{~N}$ (nitrogênio-15), também não foram observadas diferenças estatísticas entre os protocolos de extração de lipídeos ( $>00,05$; Tabela 2). Os valores médios $\delta^{15} \mathrm{~N}$ das amostras desengorduradas variaram de 6,69 e 6,88 \%o entre mínimo e máximo, respectivamente, com uma amplitude de variação de $0,19 \%$.

Tabela 2. Análise estatística dos valores de $\delta^{15} \mathrm{~N}$ do tecido muscular de juvenis de pacu $P$. mesopotamicus, considerando amostras desengorduradas por diferentes protocolos de extração da fração lipídica.

\begin{tabular}{|c|c|c|}
\hline \multirow[b]{2}{*}{ Fatores } & \multicolumn{2}{|r|}{ Estatística } \\
\hline & Valor de F & Valor de $P$ \\
\hline Quantidade de solvente (Q) & 3,09 & 0,0701 \\
\hline Frequência de Extração (F) & 0,07 & 0,9283 \\
\hline Interação Q x F & 2,21 & 0,1092 \\
\hline Coeficiente de Variação (\%) & 2,33 & \\
\hline Médias para & & $\delta^{15} \mathbf{N}(\% o)$ \\
\hline \multicolumn{3}{|c|}{ Quantidade de Solvente (mL/g de amostra seca) } \\
\hline $5 \mathrm{~mL}$ & & $6,78 \pm 0,07$ \\
\hline $10 \mathrm{~mL}$ & & $6,79 \pm 0,16$ \\
\hline $20 \mathrm{~mL}$ & & $6,81 \pm 0,18$ \\
\hline
\end{tabular}

Frequência de Extração ( $n^{\circ}$ de exposição ao solvente)

$\begin{array}{lc}3 \text { vezes } & 6,88 \pm 0,16 \\ 6 \text { vezes } & 6,69 \pm 0,11 \\ 9 \text { vezes } & 6,81 \pm 0,03\end{array}$

- Extração de lipídeos por método a frio, com o solvente hexano.

Quanto à eficiência de extração da gordura, os protocolos testados apresentaram resultados semelhantes entre as quantidades de solvente ( $p>0,05$; Tabela 3 ) e não houve efeito da interação entre os fatores $(p>0,05)$. Já para a frequência de extração, o conteúdo remanescente de gordura foi ligeiramente menor $(\mathrm{p}<0,05)$ nas frequências de seis e nove vezes $(\sim 0,44$ e $0,37 \%$, respectivamente) em relação à de três vezes $(\sim 0,60 \%)$. Contudo, ressalta-se que não houve diferenças isotópicas ( $p>0,05)$ entre as amostras desengorduradas (Tabelas 1 e 2). Baseando em metodologia de extração similar ao do presente trabalho (com $10 \mathrm{~mL}$ de solvente hexano e frequências de extrações de 2, 3, 4, 5 e 6 vezes), Marques (2010) também verificou efeito da frequência de extração sobre o teor de gordura remanescente, em amostras de tecido muscular, com médias de 2,91 a $0,98 \%$ nas extrações de duas a quatro vezes e de $0,13 \%$ de gordura remanescente na frequência de seis vezes. 
Tabela 3. Análise estatística dos valores médios de teor de extrato etéreo do tecido muscular de juvenis de pacu $P$. mesopotamicus, considerando amostras desengorduradas por diferentes protocolos de extração da fração lipídica.

\begin{tabular}{lcc}
\hline & \multicolumn{2}{c}{ Estatística } \\
\cline { 2 - 3 } Fatores & Valor de F & Valor de P \\
\hline Quantidade de solvente (Q) & 1,55 & 0,2632 \\
Frequência de Extração (F) & 4,89 & 0,0366 \\
Interação Q x F & 1,14 & 0,3965 \\
\hline
\end{tabular}

Coeficiente de Variação (\%)

14,7

Médias para Teor de Lipídeos (\%)

Quantidade de Solvente (mL/ g de amostra seca)

$\begin{array}{ll}5 \mathrm{~mL} & 0,51 \pm 0,21 \\ 10 \mathrm{~mL} & 0,40 \pm 0,15 \\ 20 \mathrm{~mL} & 0,51 \pm 0,12\end{array}$

Frequência de Extração ( ${ }^{\circ}$ de exposição ao solvente)

$\begin{array}{ll}3 \text { vezes } & 0,60 \pm 0,20 \mathrm{a} \\ 6 \text { vezes } & 0,44 \pm 0,07 \mathrm{~b} \\ 9 \text { vezes } & 0,37 \pm 0,10 \mathrm{~b}\end{array}$

Médias seguidas de mesma letra não diferem entre si pelo teste de Tukey (p>0,05).

Extração de lipídeos por método a frio, com o solvente hexano. Teor de lipídeos da amostra com base na matéria seca.

As semelhanças entre os protocolos de extração de gordura para a quantidade de solvente podem estar relacionadas com o percentual do conteúdo lipídico no tecido alvo. Lima (2010) verificou teor lipídico em cerca de 7,40 \% para o tecido muscular de juvenis de pacu; já para demais tecidos como ossos e pele, o conteúdo lipídico aumentou para 10 e 25\%, respectivamente. Assim, provavelmente, para tecidos mais gordurosos será necessário avaliar os respectivos protocolos de extração.

Contrastando o teor lipídico do tecido muscular na amostra engordurada (controle), que foi de $7,44 \pm 0,02 \%$, verificaram-se diferenças $(\mathrm{p}<0,05)$ entre a amostra controle e as desengorduradas (Figura 3). A eficiência de extração variou de 92 a $95 \%$ entre frequência de extração e quantidade de solvente. Marques (2010) também verificou uma eficiência acima de 90\%, em metodologia de extração similar, da ordem de 91 a $96 \%$ nas frequências de exposição de cinco e seis vezes, respectivamente ( 0,53 e 0,13\% de gordura remanescente na amostra desengordurada), em comparação à amostra controle com 6,06 \pm $0,5 \%$ de gordura. 
Figura 1. Valores médios de teor de lipídeos no tecido muscular de juvenis de pacu $P$. mesopotamicus engordurado e desengordurado por diferentes protocolos de frequiência de extração (3, 6 e 9 vezes de exposição ao solvente) e quantidade de solvente $(5,10$ e $20 \mathrm{~mL} / \mathrm{g}$ de amostra seca). Teor de lipídeos com base na matéria seca. Médias seguidas de mesma letra não diferem entre si pelo teste de Tukey $(p>0,05)$.

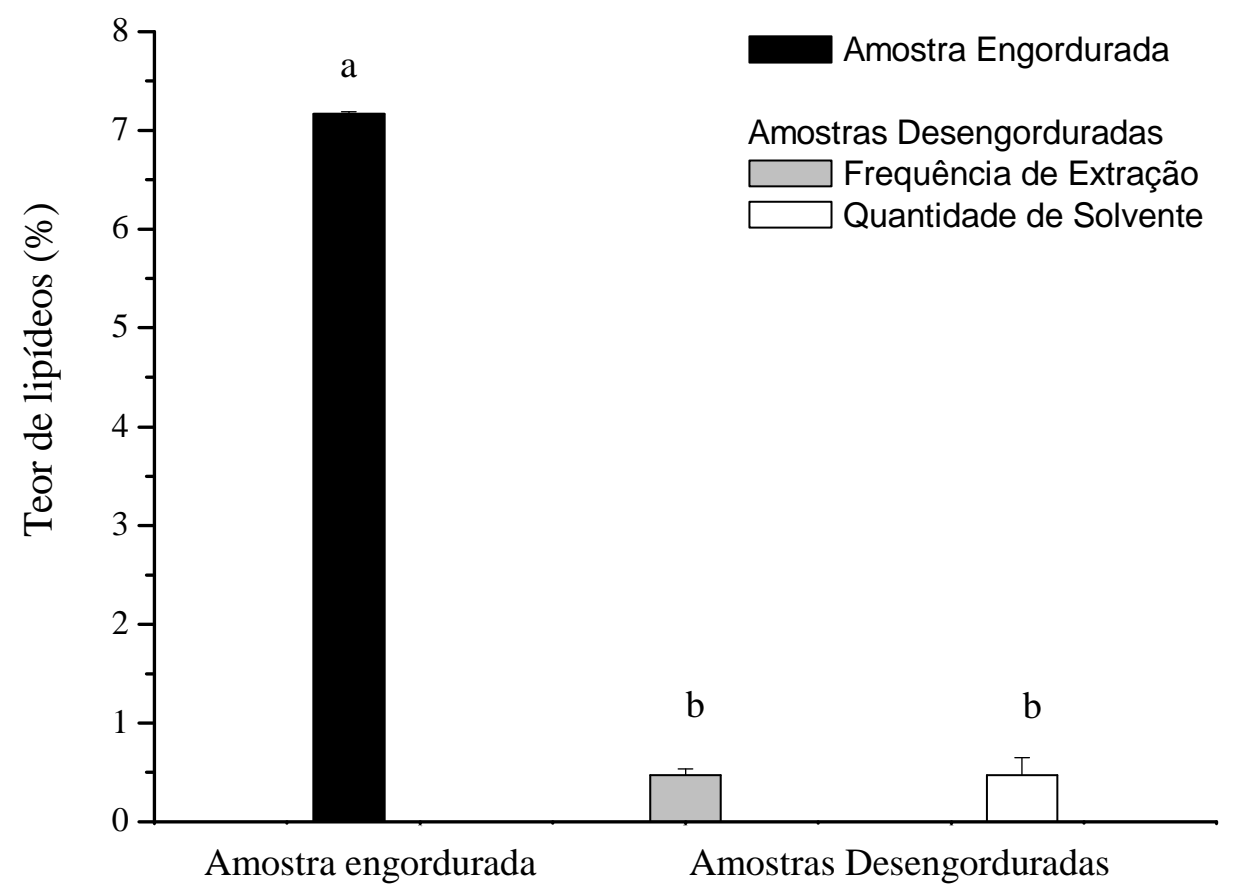

Tecido muscular

Isotopicamente, a composição do material engordurado (controle) também foi diferente $(\mathrm{p}<0,05)$ em relação ao tecido desengordurado para os valores de $\delta^{13} \mathrm{C}$ (Figura 2). 
Figura 2. Valores de $\delta^{13} \mathrm{C}(\%)$ do tecido muscular de juvenis de pacu $P$. mesopotamicus engordurado e desengordurado por diferentes protocolos de frequiência de extração $(3,6$ e 9 vezes de exposição ao solvente) e quantidade de solvente $(5,10$ e $20 \mathrm{~mL} / \mathrm{g}$ de amostra seca). Médias seguidas de mesma letra não diferem entre si pelo teste de Tukey $(\mathrm{p}>0,05)$.

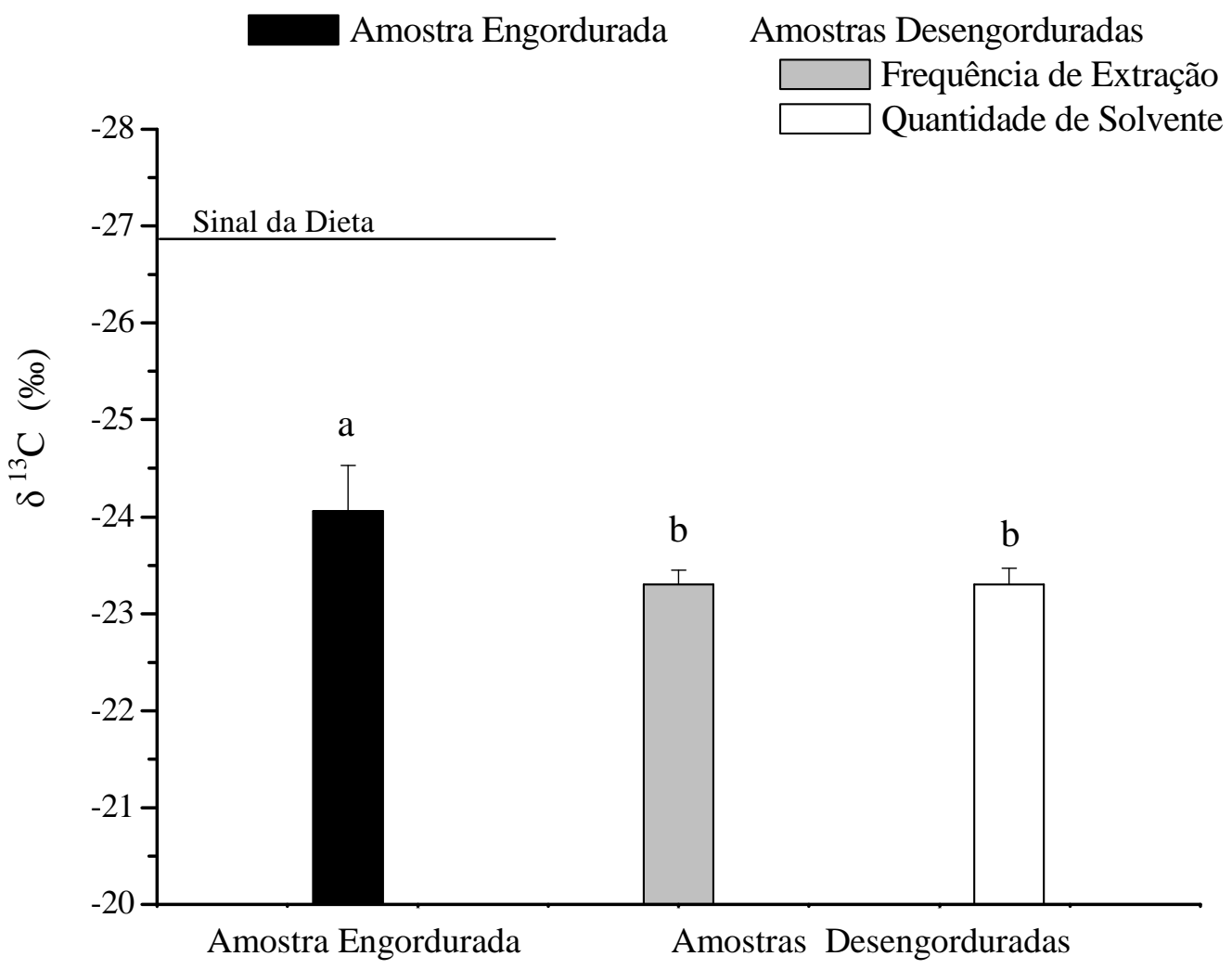

Tecido Muscular

A amostra engordurada apresentou um sinal isotópico de $-24,06 \pm 0,47 \%$ e, após a extração da gordura, as amostras desengorduradas passaram a apresentar um valor de $-23,30 \pm 0,06 \%$ (Figura 4), ou seja, as amostras engorduradas apresentaram-se mais pobres em carbono-13 que as desengorduradas. A extração da fração lipídica das amostras é um procedimento preconizado para as análises isotópicas, baseando-se no fundamento de que a fração lipídica é mais pobre em carbono-13 que os carboidratos e as proteínas, e isso pode alterar o valor da composição isotópica do tecido analisado, deixando-o mais leve, ou seja, mais pobre em carbono-13 (FOCKEN, 2004; GAVE-SIESSEGGER et al., 2004 a,b; SOTIROPOULOS et al., 2004).

Uma interpretação prática para o efeito da extração de gordura sobre composição isotópica das amostras é a análise dos resultados comparativamente ao sinal isotópico da fonte alimentar, que pode ser observado na Figura 4. Considerando que os animais, no momento da coleta, estavam recebendo uma dieta com sinal isotópico médio de $-26,85 \%$ (dieta recente); a tendência com o tempo é, isotopicamente, o animal se aproximar do sinal da respectiva dieta. Assim, a amostra engordurada expressou um valor de 
$\delta^{13} \mathrm{C}$ indicando estar mais próxima do sinal da dieta. Ao se extrair a gordura, as amostras apresentaram-se em patamar um pouco mais distante da dieta consumida, variando em $0,76 \%$. De fato, a extração do componente lipídico das amostras pode alterar o sinal isotópico dos mesmos, como também foi mostrado no tecido muscular de lula (RUIZ-COOLEY et al. 2011). Considerando que em análises isotópicas assume-se um erro analítico da ordem de 0,2 \%o para o carbono (DUCATTI, 2004); diferenças acima de 0,5 a $1 \%$ podem refletir alterações isotópicas importantes, principalmente quando se trata de interpretações em dados pontuais.

Para os isótopos de nitrogênio-15, amostras engorduradas e desengorduradas apresentaram sinais isotópicos semelhantes (p>0,05; Figura 5), com médias de 7,05 $\pm 0,17 \%$ e 6,79 $\pm 0,1 \%$ o, respectivamente, com amplitude de variação de $0,26 \%$, indicando que na extração dos lipídeos pelos protocolos testados não ocorreu alterações da fração nitrogenada que viesse modificar significativamente a razão isotópica ${ }^{15} \mathrm{~N} /{ }^{14} \mathrm{~N}$ da amostra. Lima (2010) também verificou que a extração de gordura pelo método a frio (em protocolo similar) não proporcionou diferenças isotópicas para o nitrogênio-15, entre amostra engordurada e desengordurada, diferentemente do que foi observado quando da extração a quente, o outro método testado pelo autor. Um dos inconvenientes da extração lipídica para análises isotópicas é justamente a lixiviação dos componentes, que contêm em sua molécula o nitrogênio (aminoácidos), como resultado desse procedimento, alterando também a composição isotópica do animal em nitrogênio-15 (SOTIROPOLOUS et al., 2004). 
Figura 3. Valores de $\delta^{15} \mathrm{~N}(\%)$ do tecido muscular de juvenis de pacu P. mesopotamicus engordurado e desengordurado por diferentes protocolos de frequência de extração (3,6 e 9 vezes de exposição ao solvente) e quantidade de solvente $(5,10$ e $20 \mathrm{~mL} / \mathrm{g}$ de amostra seca). Médias seguidas de mesma letra não diferem entre si pelo teste de Tukey $(\mathrm{p}>0,05)$.

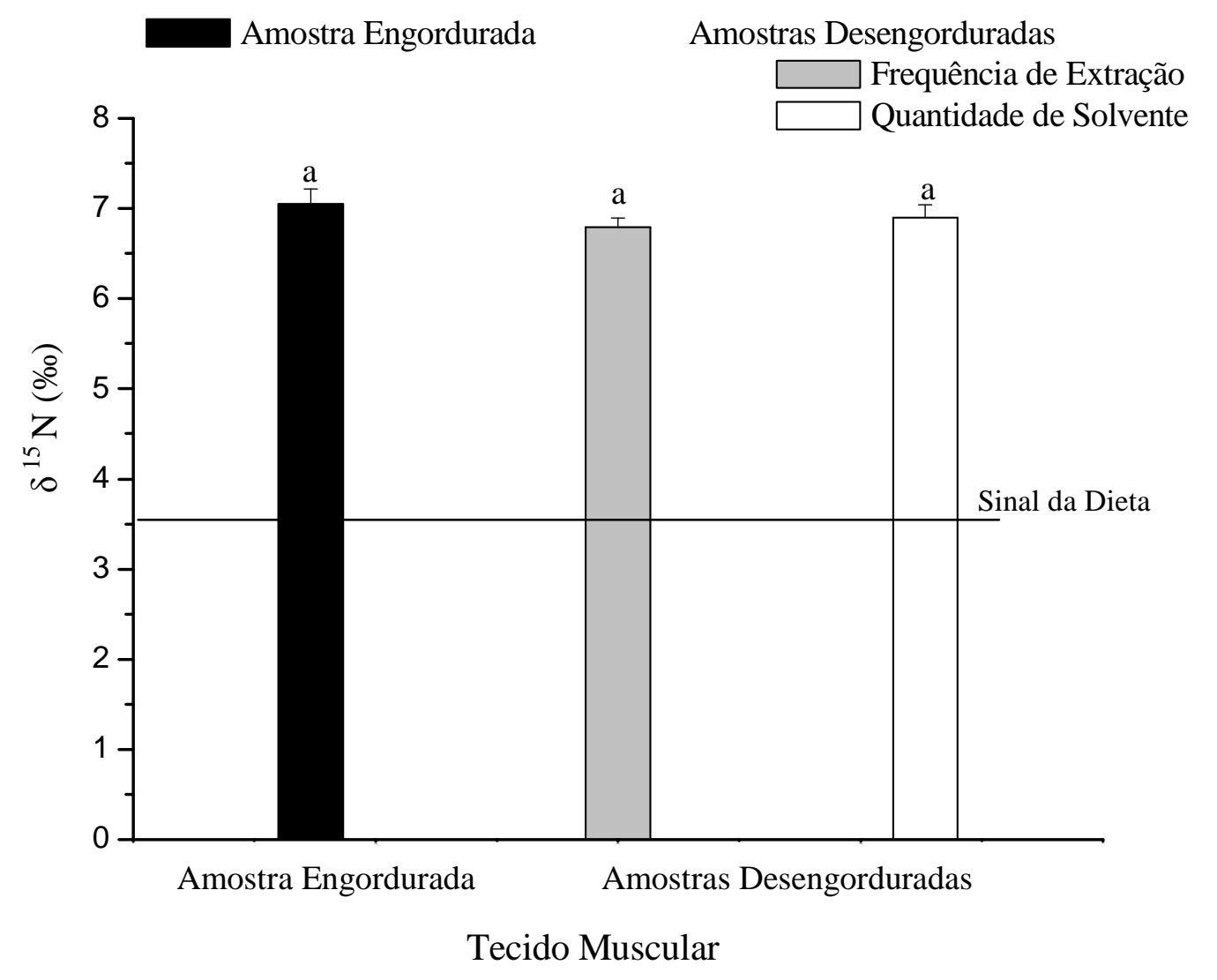

Em suma, para os isótopos de carbono-13, a extração da gordura de amostras de tecido muscular resultou em amostra mais enriquecida neste isótopo, em relação ao material engordurado (controle). Para os valores de nitrogênio-15, os protocolos utilizados não alteraram os valores de $\delta^{15} \mathrm{~N}$, sendo as constituições isotópicas semelhantes entre a amostra controle e as amostras submetidas à extração lipídica. Considerando que a metodologia de extração com o uso do solvente hexano é menos onerosa e utiliza-se um solvente menos tóxico, esses protocolos foram eficientes, na extração de lipídeos do respectivo tecido alvo, visando análises isotópicas. A menor frequência de extração proporcionou um conteúdo lipídico remanescente ligeiramente maior; contudo, as variações que foram de ordem de 0,16 a 0,23\% de lipídeos não resultaram em diferenças isotópicas significativas no tecido muscular. As diferentes quantidades de solvente proporcionaram eficiências de extração semelhantes, o que abre perspectivas para o uso mais econômico do solvente no processo de extração. Entretanto, ressalta-se que quantidade de solvente utilizada deve se adequar às características físicas das amostras, com intuito de facilitar o manuseio das mesmas quando da retirada da fase líquida, evitando a remoção das partículas sólidas. Deve-se também ter o cuidado em permitir a decantação da fase sólida antes da retirada do sobrenadante. 
Outras investigações estão sendo focadas para protocolos de extração de lipídeos de diferentes tecidos alvos, tendo em vista as variações quali-quantitativas do conteúdo lipídico entre os tecidos e o uso conjunto de dois solventes, com característica polar e apolar, para comparar a eficiência do procedimento de extração e suas possíveis interferências nos sinais isotópicos das amostras desengorduradas.

\section{CONCLUSÃO}

As quantidades de solvente apresentaram eficiências semelhantes na extração da fração lipídica; e as frequências de extração de seis e nove vezes foram ligeiramente mais eficientes na remoção da gordura do tecido muscular. Entretanto, as composições isotópicas mantiveram-se semelhantes entre as amostras desengorduradas pelos diferentes protocolos de extração, tanto para o $\delta^{13} \mathrm{C}$ como para o $\delta^{15} \mathrm{~N}$.

Em relação ao material engordurado (amostra controle), a extração de lipídeos deixou o tecido muscular desengordurado ligeiramente mais rico em $\delta^{13} \mathrm{C}$, sem provocar alterações significativas nos valores de $\delta^{15} \mathrm{~N}$, indicando que os protocolos de extração foram eficientes, na remoção da fração lipídica do tecido alvo estudado, para análises isotópicas de amostras desengorduradas.

\section{AGRADECIMENTOS}

Os autores agradecem a Fundação de Amparo à Pesquisa do Estado de São Paulo - FAPESP pelo apoio financeiro nos Processos 2008/58931-1 e 2008/ 58932-8.

\section{REFERÊNCIAS}

A.O.A.C. Official Methods of Analysis of AOAC International, 17th ed., Association of Official Analytical Chemists: Arlington, 2003, apêndice E.

ABIMORAD, E.G., CARNEIRO, D.J., 2007. Digestibility and performance of pacu (Piaractus mesopotamicus) juveniles — fed diets containing different protein, lipid and carbohydrate levels. Aquaculture Nutrition. 2007 13; 1-9

BRUM, A. A. S. Métodos de extração e qualidade da fração lipídica. 2004. 66lf. Dissertação (Mestrado)- Escola Superior de Agricultura Luiz de Queiroz, 2004.

CONCEIÇÃO, L.E.C., MORAIS, S., ARAGÃO, C., 2007. Fluxos de nutrientes em larvas de peixes: aplicação de técnicas com marcadores isotópicos e de modelação. R. Bras. Zootec., 36, 11-20.

DUCATTI, C. Isótopos estáveis ambientais. Botucatu: Universidade Estadual Paulista, 2004. Apostila.

DUCATTI, C., 2007. Aplicação dos isótopos estáveis em aquicultura, 2007. R. Bras. Zootec., 36, p.0110.

FOCKEN, U. Feeding fish with diets of different rations of $\mathrm{C}_{3}$ - and $\mathrm{C}_{4}$-plant-derived ingredients: a laboratory analysis with implications for the back-calculation of diet from stable isotope data. Rapid Communications in Mass Spectrometry, v. 18, p. 2087-2092. 2004.

GANDHI, A.P., JOSHI, K.C., KRISHNA, J., PARIBAR, D.C., SRIVASTAV, P.R., KAWALKAR, J., JAIN, S.K., TRIPATHI, R.N. Studies on alternative solvents for the extraction of oil soybean.

International Journal of Food Science and Technology, 38, 3, 369-375, 2003.

Nucleus Animalium, v.4, n.1, maio 2012 
GAVE-SIESSEGGER, J., FOCKEN, U., ABEL, H., BECKER, K. Individual protein balance strongly influences $\delta^{15} \mathrm{~N}$ and $\delta^{13} \mathrm{C}$ values in Nile tilapia, Oreochromis niloticus. Naturwissenschaften. 91, 90-93, 2004a.

GAVE-SIESSEGGER, J., FOCKEN, U., MUETZEL, S., ABEL, H., BECKER, K. Feeding level and individual metabolic rate affect $\delta^{13} \mathrm{C}$ and $\delta^{15} \mathrm{~N}$ values in carp: implications for food web studies.

Oecologia, 138, 175-183, 2004b.

GU, B.; SCHELL, D. M.; ALEXANDER, V. Stable Carbon and nitrogen Isotopic Analysis of the Plankton Food Web in a Subarctic Lake. Canadian of Journal Fisheries and Aquatic Science, Ottawa, v. 51, p. 1338-1344, 1994.

JOMORI, R.K., DUCATTI, C., CARNEIRO, D.J., PORTELLA, M.C. Stable carbon $\left(\delta^{13} \mathrm{C}\right)$ and nitrogen $\left(\delta^{15} \mathrm{~N}\right)$ isotopes as natural indicators of live and dry food in Piaractus mesopotamicus (Holmberg, 1887) larval tissue. Aquaculture Research., 39, 370-381, 2008.

MANIRAKIZA, P., COVACI, A., SCHEPENS, P. Comparative Study on Total Lipid Determination using Soxhlet, Roese-Gottlieb, Bligh \& Dyer, and Modified Bligh \& Dyer Extraction Methods. Journal of Food Composition and Analysis, 14, 93-100, 2001.

MANZKE, Naiana E. et al. Substituição do éter de petróleo por hexano na extração de gordura em. Capão do Leão: Furb, 2008. 2 p.

MARQUES, P. A.. Avaliação metodológica da extração de lipídeos e os efeitos sobre a composição isotópica de amostras desengorduradas. Monografia. 26f. Trabalho de Conclusão de Curso apresentado ao Curso de Medicina Veterinária da Faculdade Dr. Francisco Maeda/ FE, Ituverava, SP. 2010.

NELSON, D.L.; COX, M.M. Lehninger Principles of Biochemistry. 4.ed. Editora Sarvier, 2006.

RANDIN, N.S. Extraction of tissue lipids with a solvent of low toxicity. In: LOWESTEIN, J.M. (Ed.). Methods in enzimology. New York: Academic Press, 1981. v. 72, parte, p. 5-7.

RUIZ-COOLEY, R.I.; GARCIA, K.Y.; HETHERINGTON, E.D. Effects of lipid removal and preservatives on carbon and nitrogen stable isotope ratios of squid tissues: Implications for ecological studies. Journal of Experimental Marine Biology and Ecology. v.407, p.101-107, 2011.

SOTIROPOULOS, M. A.; TOM, W. M.; WASSENAAR, L. I. Effects of lipid extraction on stable carbon and nitrogen isotope analyses of fish tissues: potential consequences for food web studies. Ecology of Freshwater Fish, Oxford, v. 13, p. 155-160, 2004.

TOCHER, D. R. Metabolism and Functions of Lipids and Fatty Acids in Teleost Fish. Reviews in Fisheries Science, v. 11, n. 2., p. $107-184,2003$.

TOCHER, D. R. Fatty acid requirements in ontogeny of marine and freshwater fish, Aquaculture Research, 41, 717-732, 2010. 